\title{
Genes associated with rheumatoid arthritis and mild inflammatory arthritis. I. Major histocompatibility complex class I, II, and III allotypes
}

Alison H Puttick, D C Briggs, K I Welsh, R Vaughan, Elizabeth A.Williamson, M Boyce, R K Jacoby, Valerie E Jones

\begin{abstract}
Patients with mild inflammatory arthritis (IA) were compared with patients with definite rheumatoid arthritis (RA) for abnormal frequencies of major histocompatibility complex (MHC) antigens and haplotypes to determine whether a genetic predisposition either to $\mathbf{R A}$ or to mild self-limiting arthritis/arthralgia was present in the patients with IA. In general the MHC antigens with abnormal frequencies found in patients with IA differed from those in patients with RA and were mainly at the $A$ and $B$ loci. In patients with IA the frequencies of HLA-A24, A25, B27, and B35 antigens were significantly higher than those of controls and HLA-DR5 and C4A4 were slightly raised. In contrast, in patients with RA abnormal frequencies of the MHC antigens DR4 and DR2 and the extended haplotypes associated with them [B62 BfS C4A3 C4B3 DR4 GLO2] and [B7 BfS C4A3 C4B1 DR2] confirmed the observations reported on other white populations. Thus MHC antigen associations with IA and RA differ sufficiently to suggest a different genetic basis for the two conditions.
\end{abstract}

It is well established that the aetiopathogenesis of rheumatoid arthritis (RA) involves both genetic and environmental factors. Major histocompatibility complex (MHC) genes and HLADR4 in particular have played an important though not exclusive part in genetic susceptibility to RA. ${ }^{1}$ Not all white patients with RA are DR4 positive, some have DR1 or other DR alleles, and indeed not all DR4 positive individuals carry the DR4 subtypes which appear to confer susceptibility to RA-namely Dw4, Dw14, and Dw15. Recent data suggest, however, that shared epitopes on DR4 and DR1, which are present on the third hypervariable region of DR $\beta 1$ molecules, are an important component of the MHC gene encoding susceptibility to RA (reviewed in ref 2).

At onset of symptoms it is often difficult to distinguish clinically between a prognosis of definite RA and mild self-limiting arthralgias or inflammatory arthritis. ${ }^{3}$ In future, genetic markers may aid this prognosis. Moreover, genetic factors may not only contribute to susceptibility to mild inflammatory arthritis but also protect the patient against development of these symptoms into definite RA. In support of this hypothesis it has often been suggested that DR4 is related to severity of RA rather than susceptibility to the disease. ${ }^{45}$ The debate depends in part on ascertainment-that is, the classification of RA. Recently the American Rheumatism Association (ARA) criteria for classification of RA have been revised ${ }^{6}$ and the new definition of RA closely parallels the old definition of definite or classical RA. 'Probable' and 'possible' RA are no longer classified as RA and together with other undiagnosable forms of arthritis have been classified by us as mild inflammatory arthritis (IA). For clarity we continue to define our patients with $\mathrm{RA}$ as definite RA.

To look for genetic differences between mild forms of arthritis and RA we studied both MHC and non-MHC genes in a group of patients with IA and compared them with patients who had already developed definite or classical RA. First degree relatives of these patients were included in the study to enable us to assign serological markers into haplotypes on each chromosome. In this paper we report the differences in MHC antigen and gene frequencies and in the accompanying paper we examine associations of $\mathrm{MHC}$ with non-MHC genes-namely, those linked to immunoglobulin genes and to complement (C3) genes. ${ }^{8}$

\section{Patients and methods}

PATIENTS

Sixty one white patients diagnosed as having definite or classical $\mathrm{RA}^{7}$ were included in the study; of these, data from 27 were reported in our previous study. ${ }^{9}$ Twenty patients were from 10 multicase families with two patients in each family. For estimation of individual antigen frequencies patients other than the probands of the 10 multicase families were excluded, whereas when RA associated chromosomes were analysed both patients in each family were included. A few patients were excluded when seropositivity for rheumatoid factor was analysed because only one serum sample from each patient was available to test; all other patients were tested at least twice over several years.

The 49 patients with IA had unclassified inflammatory polyarthritis or arthralgias, all were white and most were included in earlier studies of immune complexes and human parvovirus infection in early arthritis. ${ }^{10-12}$ Thus many patients had been seen regularly over several years and none had developed diagnosable forms of arthritis-including spondarthritis-though five had evidence of a parvovirus infection. Four patients were seropositive for rheumatoid factor and there was a family history of RA in three patients. Patients with IA and $R A$ were attending outpatient rheumatology clinics in Exeter and Torquay. 
FAMILY MEMBERS

To establish MHC haplotypes at least two first degree relatives of the 49 patients with IA and of the 41 patients with $R A$ who were not included in our previous study ${ }^{9}$ were tissue typed. Where feasible both parents were typed, then children, siblings or parents' siblings where necessary.

\section{CONTROLS}

Individual HLA frequencies were obtained from a panel of 138 donors for HLA-A and B and 126 donors for HLA-DR from the Exeter tissue typing laboratory. Frequencies of individual complement components $\mathrm{C} 4 \mathrm{~A}$ and $\mathrm{C} 4 \mathrm{~B}$ were measured in 306 donors and factor $\mathrm{B}$ (Bf) in 303 donors at Guy's Hospital tissue typing laboratory; complotype frequencies were compared with reported values from 42 white normal controls. ${ }^{13}$ In the absence of suitable control data glyoxalase-1 and haplotype frequencies were compared between patients with RA, patients with IA, and family members according to the method of Raum et al. ${ }^{14}$ In brief, haplotypes found in any patient with RA or IA-'RA or IA haplotypes'-were compared with those found only in unaffected family members-non-RA and non-IA haplotypes'. Haplotypes occurring in more than one person in a family were counted only once.

\section{TISSUE TYPING}

Typing of HLA-A, B, and DR antigens was carried out by a conventional microcytotoxicity assay with antisera from the Exeter and Guy's Hospital tissue typing laboratories. All patients with RA and IA and population controls were

Table 1: $H L A-A$ and $B$ antigen frequencies in patients with rheumatoid arthritis, patients with inflammatory arthritis, and controls

\begin{tabular}{|c|c|c|c|c|c|}
\hline \multirow[t]{2}{*}{$H L A$ antigen } & \multicolumn{3}{|c|}{ Frequency $(\%)$ of $H L A$ antigens in: } & \multicolumn{2}{|c|}{ Significance } \\
\hline & $\begin{array}{l}\text { Patients with } \\
R A^{*} \\
(n=51)\end{array}$ & $\begin{array}{l}\text { Patients with } \\
I A^{*} \\
(n=49)\end{array}$ & $\begin{array}{c}\text { Controls } \\
(n=138)\end{array}$ & $\chi^{2}$ & $p$ \\
\hline $\begin{array}{l}\text { A24 } \\
\text { A25 } \\
\text { B27 } \\
\text { B35 } \\
\text { B62 }\end{array}$ & $\begin{array}{c}7 \cdot 8 \\
<2 \cdot 0 \dagger \\
4 \cdot 0 \\
9 \cdot 8 \\
27 \cdot 5^{\mathrm{e}}\end{array}$ & $\begin{array}{c}24 \cdot 5^{\mathrm{a}} \\
8 \cdot 2^{\mathrm{b}} \\
22 \cdot 4^{\mathrm{c}} \\
20 \cdot 4^{\mathrm{d}} \\
8 \cdot 2^{\mathrm{e}}\end{array}$ & $\begin{array}{c}10 \cdot 8^{\mathrm{a}} \\
<1.4^{\mathrm{b}} \dagger \\
7 \cdot 9^{\mathrm{c}} \\
7 \cdot 9^{\mathrm{d}} \\
15 \cdot 9^{-}\end{array}$ & $\begin{array}{l}24.38 \\
\text { b7.94 } \\
\text { c5.97 } \\
\text { d } 4.43 \\
\text { e5.05 }\end{array}$ & $\begin{array}{l}<0.05 \\
<0.01 \\
<0.02 \\
<0.05 \\
<0.05\end{array}$ \\
\hline
\end{tabular}

* $\mathrm{RA}=$ rheumatoid arthritis; IA = inflammatory arthritis.

tNo individual carried this antigen.

Table 2: HLA-DR frequencies in patients with rheumatoid arthritis, patients with inflammatory arthritis, and controls

\begin{tabular}{|c|c|c|c|c|c|}
\hline \multirow[t]{2}{*}{$D R$ antigen } & \multicolumn{3}{|c|}{ Frequency (\%) of $D R$ antigens in: } & \multicolumn{2}{|c|}{ Significance } \\
\hline & $\begin{array}{l}\text { Patients with } \\
R A^{*} \\
(n=51)\end{array}$ & $\begin{array}{l}\text { Patients with } \\
I A^{*} \\
(n=49)\end{array}$ & $\begin{array}{c}\text { Controls } \\
(n=126)\end{array}$ & $\chi^{2}$ & $p$ \\
\hline $\begin{array}{l}1 \\
2 \\
3 \\
4\end{array}$ & $\begin{array}{l}21 \cdot 6 \\
11 \cdot 8^{a} \\
13 \cdot 7^{b} \\
74 \cdot 5^{b} \mathrm{c}\end{array}$ & $\begin{array}{l}14 \cdot 3 \\
30 \cdot 6 \\
24 \cdot 5 \\
42 \cdot 8^{c}\end{array}$ & $\begin{array}{l}10 \cdot 3 \\
29 \cdot 4^{\mathrm{a}} \\
27 \cdot 9^{-9} \\
38 \cdot 9^{\mathrm{b}}\end{array}$ & $\begin{array}{r}25 \cdot 19 \\
\text { b17.04 } \\
\text { c9.08 }\end{array}$ & $\begin{array}{l}<0.05 \\
<0.001 \\
<0.01\end{array}$ \\
\hline $\begin{array}{l}5 \\
6 \\
7 \\
8 \\
9\end{array}$ & $\begin{array}{l}13.7 \\
17.6 \\
11.8 \\
<2 \cdot 0+ \\
<2.0+\end{array}$ & $\begin{array}{l}26.5 \\
16.3 \\
18.4 \\
<2.0+ \\
<2.0+\end{array}$ & $\begin{array}{r}15 \cdot 1 \\
27 \cdot 0 \\
20 \cdot 0 \\
4 \cdot 8 \\
3 \cdot 2\end{array}$ & & \\
\hline
\end{tabular}

* $R A=$ rheumatoid arthritis; IA=inflammatory arthritis.

tNo individual carried these antigens.
DR typed by the microcytotoxicity assay, but DR antigens in many family members were identified by restriction fragment length polymorphisms ${ }^{15}$ using a scheme similar to that of Bidwell et al. ${ }^{16}$ If necessary, restriction fragment length polymorphisms were confirmed by the microcytotoxicity assay. Procedures used for complement and glyoxalase-1 typing are outlined in our previous publication. ${ }^{9}$ Assignment of $\mathrm{C} 4 \mathrm{~A}$ and $\mathrm{C} 4 \mathrm{~B}$ phenotypes, in particular the null alleles $\mathrm{C} 4 \mathrm{AQO}$ and $\mathrm{C} 4 \mathrm{BQO}$, was done with data from family members.

\section{STATISTICAL ANALYSIS}

Differences in allele or haplotype frequencies between patients and control populations were assessed for statistical significance using the $\chi^{2}$ test, with Yates's correction for small numbers. No adjustment was made for the number of antigens tested. As not all patients or controls could be assigned a complete haplotype, the numbers of individuals included in each analysis are given in each table.

\section{RHEUMATOID FACTOR}

Seropositivity for rheumatoid factor was measured by the latex agglutination test with human IgG as antigen (Rapitex-RF kit, Behringwerke).

\section{Results}

HLA-A, B, AND DR FREQUENCIES

Frequencies of individual HLA-A, B, and DR antigens in patients with $R A$ and IA were compared with Exeter controls. Table 1 lists only those A and B antigen frequencies which differed significantly; table 2 gives the frequencies of nine DR antigens. No differences in frequencies would remain significant, except that of DR4, if adjustment were made for the number of antigens tested. In patients with IA antigen frequencies of HLA-A24, A25, B27, and $B 35$ were significantly raised and gene frequencies of HLA-A25, B27, and B35 were also significantly raised (data not given). The frequency of DR5 was high in patients with IA, though not significantly higher than in patients with RA and controls. These results contrasted with the expected increase in DR4 and decrease in frequency of DR2 in the patients with RA. HLA-B62 was raised in patients with RA, but the difference was significant only when compared with patients with IA because the frequency in the patients with IA was considerably lower than in controls. Thus patients with IA have abnormal frequencies of certain HLA allotypes but these do not overlap with abnormal frequencies found in RA.

\section{FREQUENCIES OF HLA PAIRS}

Individuals were also analysed for pairs of HLA antigens, whether these antigens occurred on the same or the opposite chromosome. Frequencies of certain B or DR antigens, which were not significantly raised when calculated as individual antigen frequencies, became signifi- 
Table 3: HLA antigen frequencies in men and women

\begin{tabular}{|c|c|c|c|c|c|c|c|c|}
\hline \multirow[t]{3}{*}{ Antigen } & \multicolumn{6}{|c|}{ Frequency (\%) of $H L A$ antigens in: } & \multicolumn{2}{|c|}{ Significance } \\
\hline & \multicolumn{2}{|c|}{ Patients with $R A^{*}$} & \multicolumn{2}{|c|}{ Patients with $I A^{*}$} & \multicolumn{2}{|l|}{ Controls } & \multirow[t]{2}{*}{$\overline{\chi^{2}}$} & \multirow[t]{2}{*}{$p$} \\
\hline & $\begin{array}{l}\text { Men } \\
(n=12)\end{array}$ & $\begin{array}{l}\text { Women } \\
(n=44)\end{array}$ & $\begin{array}{l}\text { Men } \\
(n=10)\end{array}$ & $\begin{array}{l}\text { Women } \\
(n=39)\end{array}$ & $\begin{array}{l}M e n \\
(n=53)\end{array}$ & $\begin{array}{l}\text { Women } \\
(n=58)\end{array}$ & & \\
\hline $\begin{array}{l}\text { A25 } \\
\text { B27 } \\
\text { B35 } \\
\text { B40 } \\
\text { B62 }\end{array}$ & $\begin{array}{l}<8.3 \dagger \\
<8.3 \dagger \\
<8.3 \dagger \\
16.7 \\
33.3\end{array}$ & $\begin{array}{c}<2 \cdot 2 \dagger \\
4.5 \\
9 \cdot 1 \\
25 \cdot 0^{\mathrm{b}} \\
20.5\end{array}$ & $\begin{array}{c}<10.0 \dagger \\
30.0 \\
20.0 \\
20.0 \\
<10.0 \dagger\end{array}$ & $\begin{array}{c}10 \cdot 2^{2} \\
15 \cdot 4 \\
15 \cdot 4 \\
5 \cdot 1^{b} \\
10 \cdot 3\end{array}$ & $\begin{array}{c}<1.9+ \\
7.5 \\
9.4 \\
16.9 \\
13.2\end{array}$ & $\begin{array}{c}<1.7^{2} \dagger \\
10.3 \\
8.6 \\
12.2 \\
19.0\end{array}$ & ${ }^{2} 3.88$ & $\leqslant 0.05$ \\
\hline DR1 & $<8 \cdot 3^{c} t$ & $22 \cdot 7^{\mathrm{cd}}$ & $30 \cdot 0$ & $10 \cdot 3$ & $\begin{array}{c}\left(\begin{array}{c}n=46) \\
13 \cdot 0\end{array}\right. \\
\end{array}$ & $\begin{array}{c}(n=53) \\
9 \cdot 4^{\mathrm{u}}\end{array}$ & $\begin{array}{l}1.95 \\
\mathrm{~d} 2.43\end{array}$ & \\
\hline DR2 & $33 \cdot 3^{\mathrm{e}}$ & $6 \cdot 8^{\mathrm{ef}}$ & $40 \cdot 0$ & $28 \cdot 2^{f}$ & $28 \cdot 2$ & $22 \cdot 6$ & $\begin{array}{l}3.87 \\
6.37\end{array}$ & $\leqslant 0.05$ \\
\hline DR4 & $91 \cdot 7^{i}$ & $72 \cdot 7^{\mathrm{g} \mathrm{h}}$ & 60.0 & $38 \cdot 5^{8}$ & $36 \cdot 9^{i}$ & $35 \cdot 8^{\mathrm{h}}$ & $\begin{array}{r}88.53 \\
{ }^{8} 13.28 \\
\text { i9.32 }\end{array}$ & $\begin{array}{l}<0.03 \\
<0.01 \\
<0.001 \\
<0.01\end{array}$ \\
\hline
\end{tabular}

${ }^{*} \mathrm{RA}=$ rheumatoid arthritis; $\mathrm{IA}=$ inflammatory arthritis

$\nmid$ No individual carried these antigens.

cantly raised when found in association with DR4 in patients with RA or with DR5 in patients with IA. For example, in patients with RA there was an increased frequency of DR1 and B40 when paired with DR4 (DR4+DR1: RA $v$ control $=16.9 \% v 3.2 \% ; \chi^{2}=8.91, \mathrm{p}<0.01$. DR4+B40: RA $v$ control $=23.5 \%$ v $4 \cdot 8 \%$; $\chi^{2}=$ $12.01, \mathrm{p}<0.001)$. In patients with IA DR5 was found in association with B44 or B27; in fact these $B$ alleles were absent in only two of 13 patients with IA with DR5 (DR5+B27: IA $v$ control $=12 \cdot 2 \%$ v $1.6 \% ; \chi^{2}=6.9, \mathrm{p}<0.01$. DR5+ B44: IA $v$ control $=12 \cdot 2 \%$ v $3 \cdot 2 \% ; \chi^{2}=4 \cdot 33$, $\mathrm{p}<0.05)$.

FREQUENCIES IN MALE AND FEMALE PATIENTS The patients with RA or IA were mostly female (78\% and $79 \%$ respectively). In normal populations HLA antigens are distributed equally in

Table 4: HLA antigen frequencies in seropositive and seronegative patients with rheumatoid arthritis

\begin{tabular}{|c|c|c|c|c|c|c|}
\hline \multirow[t]{3}{*}{ Antigen } & \multicolumn{4}{|c|}{ Frequency (\%) of HLA antigens in: } & \multicolumn{2}{|c|}{ Significance } \\
\hline & \multicolumn{3}{|c|}{ Patients with $R A$} & \multirow{2}{*}{$\begin{array}{l}\text { Controls } \\
(n=138)\end{array}$} & \multirow[t]{2}{*}{$\overline{\chi^{2}}$} & \multirow[t]{2}{*}{$p$} \\
\hline & $\begin{array}{l}\text { Total } \\
(n=54)\end{array}$ & $\begin{array}{l}\text { Seropositive } \\
(n=44)\end{array}$ & $\begin{array}{l}\text { Seronegative } \\
(n=10)\end{array}$ & & & \\
\hline $\begin{array}{l}\text { A11 } \\
\text { B8 } \\
\text { B14 } \\
\text { B35 }\end{array}$ & $\begin{array}{r}14 \cdot 8 \\
31 \cdot 5 \\
7 \cdot 4 \\
9 \cdot 3\end{array}$ & $\begin{array}{c}9 \cdot 1^{a} \\
38 \cdot 6^{b} \\
2 \cdot 3^{c} \\
4 \cdot 5^{d}\end{array}$ & $\begin{array}{c}40 \cdot 0^{\mathrm{a}} \\
<10 \cdot 0^{\mathrm{b} *} \\
30 \cdot 0^{\mathrm{c}} \\
30^{\circ} 0^{\mathrm{d}}\end{array}$ & $\begin{array}{r}7 \cdot 2 \\
27 \cdot 5 \\
6 \cdot 5 \\
7 \cdot 9\end{array}$ & $\begin{array}{l}\text { a3.96 } \\
\text { b3.98 } \\
\text { c4.61 } \\
\text { d. } 3.61\end{array}$ & $\begin{array}{l}<0.05 \\
<0.05 \\
<0.05 \\
\text { NS }\end{array}$ \\
\hline $\begin{array}{l}\text { DR2 } \\
\text { DR4 }\end{array}$ & $\begin{array}{r}9 \cdot 3 \\
66 \cdot 7\end{array}$ & $\begin{array}{l}11 \cdot 4 \\
65 \cdot 9\end{array}$ & $\begin{array}{c}<10 \cdot 0^{*} \\
70 \cdot 0\end{array}$ & $\begin{array}{l}(n=126) \\
29 \cdot 4 \\
38.9\end{array}$ & & \\
\hline
\end{tabular}

*No patient carried these antigens.

Table 5: Complement component allotypes of $C 4 A$ and $C 4 B$ in patients with rheumatoid arthritis, patients with inflammatory arthritis, and controls

\begin{tabular}{|c|c|c|c|c|c|}
\hline \multirow[t]{2}{*}{ Antigen } & \multicolumn{3}{|c|}{ Frequency (\%) of C4 allotypes in: } & \multicolumn{2}{|c|}{ Significance } \\
\hline & $\begin{array}{l}\text { Patients with } \\
R A^{*} \\
(n=51)\end{array}$ & $\begin{array}{l}\text { Patients with } \\
I A^{*} \\
(n=49)\end{array}$ & $\begin{array}{l}\text { Controls } \\
(n=306)\end{array}$ & $\overline{\chi^{2}}$ & $p$ \\
\hline$\overline{C 4 A 2}$ & $2 \cdot 0^{2}$ & $4 \cdot 1^{b}$ & $15 \cdot 4^{a b}$ & \multirow{3}{*}{$\begin{array}{r}\text { as.6 } \\
\text { b3.61 } \\
\text { c2.59 } \\
\text { d5.67 } \\
\text { e6.62 } \\
\text { f } 15.66 \\
\text { 83.44 }\end{array}$} & \multirow{3}{*}{$\begin{array}{l}<0.02 \\
N S \\
\text { NS } \\
<0.02 \\
<0.02 \\
<0.001 \\
\text { NS }\end{array}$} \\
\hline $\begin{array}{l}\text { C4A4 } \\
\text { C4BQO } \\
\text { C4B1 }\end{array}$ & $\begin{array}{c}7 \cdot 8 \\
45 \cdot 1^{\mathrm{d}} \\
72 \cdot 5^{\mathrm{e} \mathrm{f}}\end{array}$ & $\begin{array}{l}14 \cdot 3^{c} \\
34 \cdot 7 \\
93 \cdot 9^{c}\end{array}$ & $\begin{array}{r}6 \cdot 5^{c} \\
27 \cdot 5^{d} \\
92 \cdot 2^{f}\end{array}$ & & \\
\hline C4B3 & $13 \cdot 7^{8}$ & $6 \cdot 1$ & $5 \cdot 6^{8}$ & & \\
\hline
\end{tabular}

* RA=rheumatoid arthritis; IA = inflammatory arthritis. men and women, but in the patient groups some abnormal frequencies were significantly higher or lower in women (A25 in IA, B40 in RA compared with IA, and DR2 in patients with RA) (table 3). The exception was DR4 in patients with RA, which was raised in both men and women. In male patients most differences were not significant owing to the small number of patients studied, but it is notable that if the frequency of an antigen was abnormally high in men in one patient group it was absent in men in the other patient group (see B27, B35, B62, and DR1).

FREQUENCIES IN RHEUMATOID FACTOR POSITIVE AND NEGATIVE PATIENTS

When patients with RA were divided into those seropositive and seronegative for rheumatoid factor, again the DR4 positive patients were evenly distributed between the two groups (table 4). Although numbers of seronegative rheumatoid patients were low, frequencies of three antigens-A11, B8, and B14-were significantly different from those of seropositive patients. When gene frequencies were calculated these differences were confirmed and the gene frequency of B35, which is in linkage disequilibrium with A11, also differed between seronegative and seropositive patients $\left(\chi^{2}=4 \cdot 18\right.$, $\mathrm{p}<0.05)$, being raised in the former.

\section{Bf, C4A, AND C4B FREQUENCIES}

When frequencies of $B f$ variants $F$ and $S$ were analysed, either as gene, allotype, or phenotype frequencies, there were no significant differences between patients with RA and those with IA or between patients and their family members or with population controls from Guy's Hospital (F allotype: RA $37 \cdot 3 \%$, IA $40.8 \%$, controls $41 \cdot 6 \%$; $S$ allotype: RA $96 \cdot 1 \%$, IA $97 \cdot 9 \%$, controls $86 \cdot 5 \%$ ).

Frequencies of some alleles of C4A and C4B were significantly different between patients with RA and controls but differences seen in patients with IA were not significant (table 5). With the exception of C4A2, abnormal frequencies of the C4A and C4B allotypes occurred either in one or the other patient group but did 
not overlap. The null allele $\mathrm{C} 4 \mathrm{BQO}$, but not C4AQO, was significantly raised in patients with RA.

\section{COMPLOTYPES}

Variations in $\mathrm{Bf}, \mathrm{C} 4 \mathrm{~A}$, and $\mathrm{C} 4 \mathrm{~B}$ frequencies were also analysed as components of HLA class III complotypes and are presented in this order. C2 was not included in our study. Comparison of complotype frequencies in patients with RA and IA was made with 42 normal individuals ( 84 haplotypes - that is, chromosomes) from Fielder et $a l^{13}$ and with 142 non-RA and non-IA associated haplotypes derived from the family members of our patients with RA and IA.
Frequencies of two complotypes (S33 and F30) were significantly higher in patients with $R A$ than in Fielder's controls $\left(\chi^{2}=5 \cdot 11, \mathrm{p}<0.05\right.$; $\chi^{2}=5.99, p<0.02$ respectively) and the frequency of S33 was also higher than in family members $\left(\chi^{2}=4.72, p<0.05\right)$. The S33 frequency was slightly raised in patients with IA but did not differ significantly from either controls or family members.

\section{EXTENDED HAPLOTYPES}

Complotypes were then analysed as 'extended haplotypes' in association with the HLA-B and DR alleles present on the same chromosome. The figure shows their distribution in 98 and 90 (a)

(c)

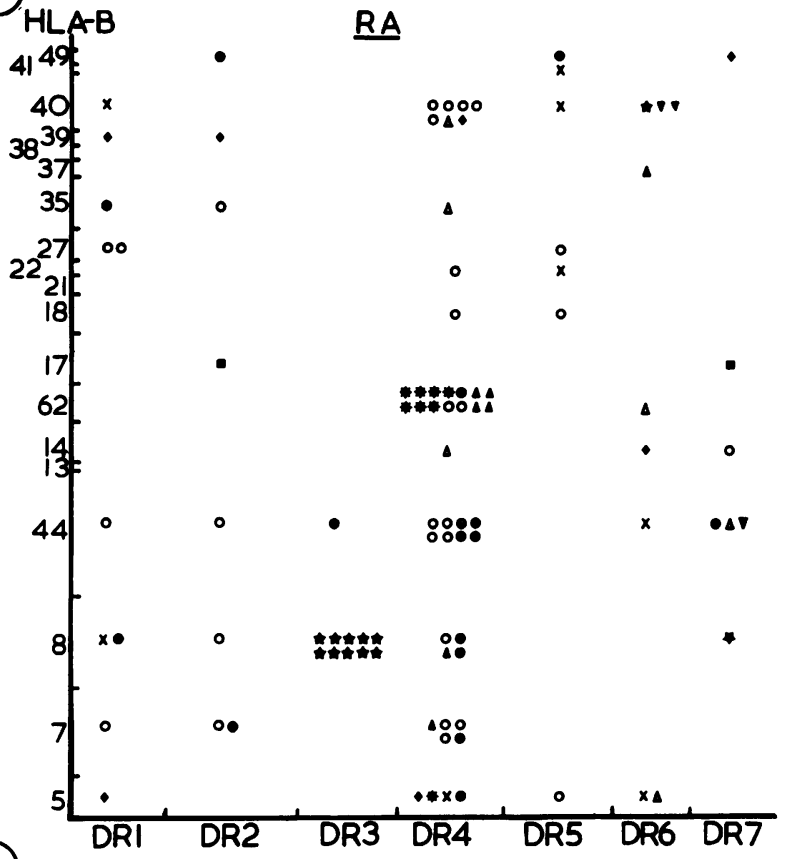

(b)

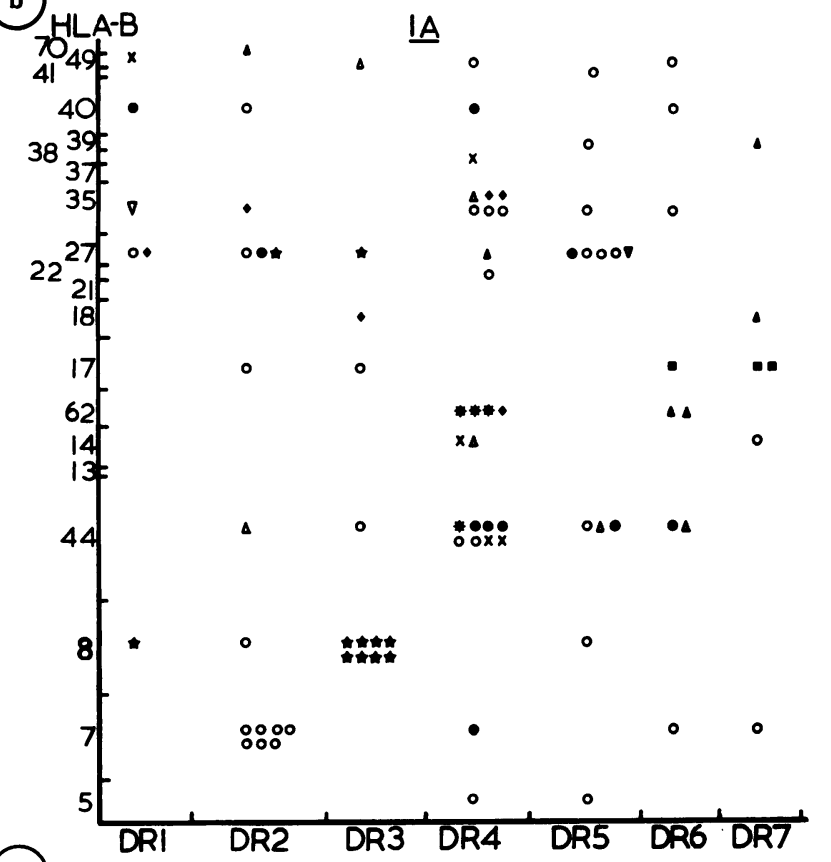

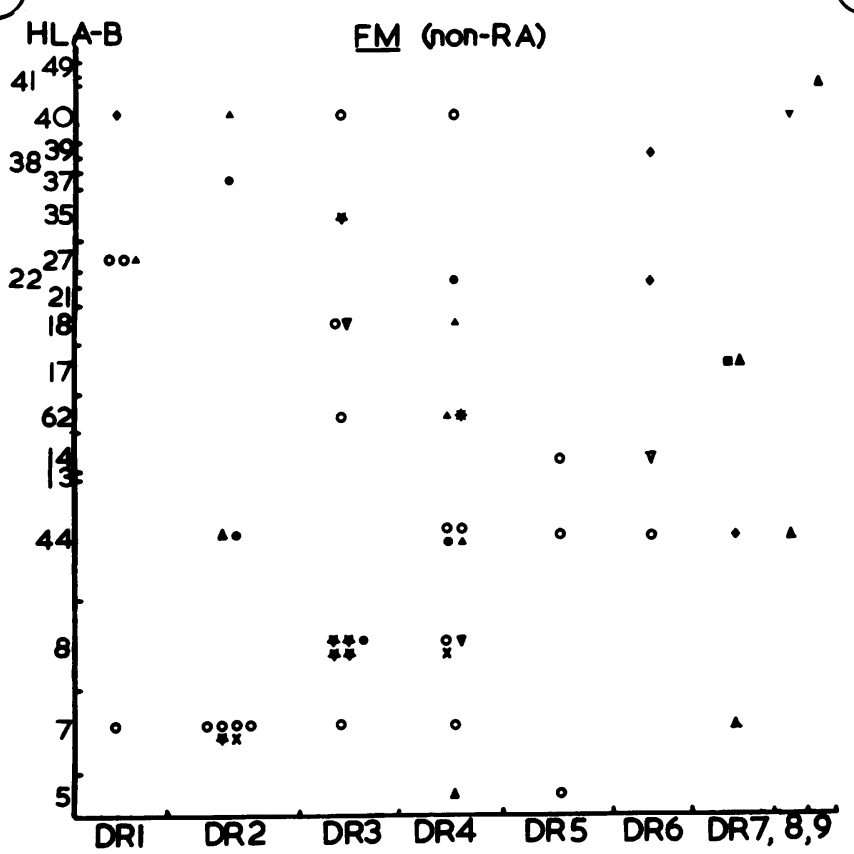

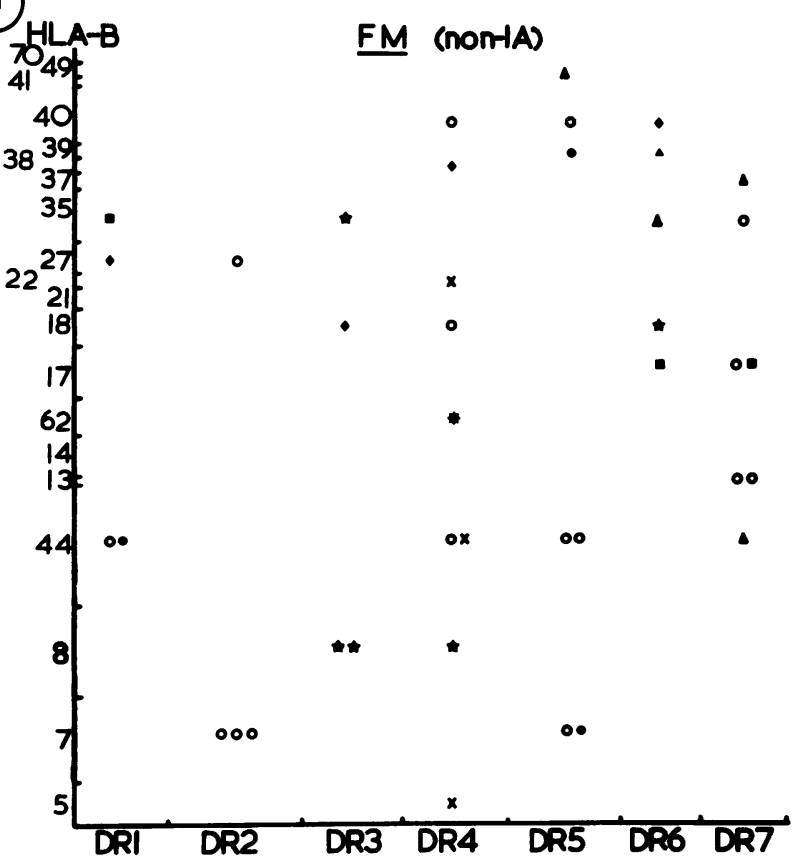

Distribution of common complotypes in relation to HLA-B and DR on the same chromosome. (a) In patients with rheumatoid arthritis (RA)(98 chromosomes); (b) in patients with inflammatory arthritis (IA) ( 90 chromosomes); ( $c$ and d) in 54 non-RA and 40 non-IA associated haplotypes of family members (FM). Complotypes are expressed as alleles of $B f, C 4 A$, and $C 4 B$ in that order. $S 31 O, S O 1 \star$, F31 $\triangle, S 33 \bullet, S 30 O, F O 1 \nabla, F 30 \times, S 42 \triangle, S 61 \square$, SO2 7 , Others $\$$. 
haplotypes from patients with $\mathrm{RA}$ and IA respectively and in 54 non-RA and 40 non-IA associated haplotypes in family members. Of the extended haplotypes evaluated, the frequency of two haplotypes was different in patients with RA than in patients with IA and family members of both patients with RA and IA. [B62 BfS C4A3 C4B3 DR4] was raised (7•1\% in patients with $\mathrm{RA}, 3.3 \%$ in patients with IA, and $2 \cdot 2 \%$ in family members) and [B7 BfS C4A3 C4B1 DR2] was lower $(1.0 \%$ in patients with RA, $7 \cdot 8 \%$ in patients with IA, and $7 \cdot 7 \%$ in family members); these differences were not significant. In patients with IA, of the 12 extended haplotypes associated with B27, five contained the complotype S31 but with several different DR alleles. In the five patients with IA carrying the rare allele HLA-A25 two had B18 with S42 and two had B39 with S31 or S42, but again with several different DR alleles.

\section{GLYOXALASE-1 FREQUENCIES}

Estimates of the gene frequencies of glyoxalase alleles 1 and 2 showed no significant differences between the two patient groups, nor between patients and controls, nor between seronegative and seropositive RA. Small differences in glyoxalase-1 phenotype frequency found between patients with RA and IA were not significant and probably reflected differences in certain haplotypes strongly represented in these patients. For example, in patients with RA the extended haplotype [B62 BfS C4A3 C4B3 DR4] was most commonly associated with glyoxalase2. In both patients with RA and IA, however, more men than women were glyoxalase-1/2 (heterozygotes), though differences were not significant (in RA: men $75.0 \%$, women $52.3 \%$; in IA: men $50.0 \%$, women $38 \cdot 5 \%$ ).

\section{Discussion}

A distinction between genes which determine susceptibility to mild self-limiting arthritis and genes which predispose to chronic RA might influence the clinical management of these patients in the early stages. In this and the accompanying paper $^{8}$ we have shown that patients with definite or classical RA differ from patients with mild arthritis in their association with MHC genes even though both groups of patients may have similarly mild symptoms (less than five ARA diagnostic criteria ${ }^{7}$ ) at onset of disease. ${ }^{3}$ We confirmed the high frequency of DR4 in our patients with RA and found a near normal frequency of DR4 in the patients with IA. Other studies have shown small but insignificant increases in DR4 frequency in patients with 'probable' or 'possible' RA - that is, less than five ARA criteria ${ }^{5}$ - and a normal frequency of DR4 among patients with RA in the population outside hospital rheumatology clinics. ${ }^{4}$ Now that the new diagnostic criteria for $\mathrm{RA}^{6}$ no longer classify 'probable' and 'possible' RA as RA these patients can be equated with our patients with IA, and therefore we conclude that DR4 is not associated with mild inflammatory arthritis.

The association of other MHC antigens with definite or classical RA was confirmed in our patients and supported previous reports (ref 9 , summarised in ref 17). Frequencies of B62 and $\mathrm{C} 4 \mathrm{~B}$ null alleles were high as was the complotype S33 and the extended haplotype [B62 S33 DR4]. ${ }^{9} 1819$ The frequency of DR1 was raised in patients with RA and not in those with IA. Although this difference was not significant, it does support the concept of the common disease susceptibility determinant for RA in the third hypervariable region of DR4 and DR1 DR $\beta 1$ molecules. ${ }^{2}$

Our studies on Bf did not support the overall increase in the BfS gene and BfSS genotype found in patients with RA by Dyer et $a l^{20}$ or the raised frequency of BfSS phenotype found in seropositive rheumatoid patients by Lanchbury et al. ${ }^{21}$ We found a significantly increased frequency of $C 4 B$ null alleles in our patients with $\mathrm{RA}$, however. A significantly raised $\mathrm{C} 4 \mathrm{BQO}$ has been found in patients with Felty's syndrome but not previously in RA. ${ }^{22}$ Despite the high frequency of C4BQO in our patients with RA there was no association with autoimmunity (seropositive RA $46.3 \%$, seronegative RA 40.0\%).

Frequencies of DR4 were raised in all RA patient groups, whether male or female, seropositive or seronegative. Therefore our seronegative patients with RA cannot be considered a separate clinical category on the basis of low DR4 frequency. ${ }^{23}$ Furthermore, B27 frequency was not increased in seronegative RA, and therefore these patients did not seem to have atypical B27 inflammatory arthropathies misclassified as RA. ${ }^{24}$ The only HLA antigens to differ significantly in frequency between seronegative and seropositive RA were A11, B8, and B14. DR2 was absent in seronegative patients with RA and, furthermore, the frequency was low in female but not in male patients with RA, which suggests that DR2 is protective in women as well as in patients with RA without rheumatoid factors. The frequency of DR5 was raised in patients with IA, though not significantly. DR5 has been associated with other connective tissue disorders, such as scleroderma, ${ }^{25}$ vinyl chloride disease, and pauciarticular onset juvenile arthritis, ${ }^{26}$ but not with RA.

The overall lack of shared HLA antigens associated with patients with RA and IA reinforced the distinct clinical categories of these patient groups and the distinction was further emphasised in male patients. In male patients with IA the frequencies of three HLA antigens-B27, B35, and DR1-were raised above male control frequencies and these three antigens were absent from male patients with RA, suggesting that in men these antigens may be associated with susceptibility to IA but may protect against the progression of IA into RA. On the other hand, the rare A25 allele present in patients with IA, but absent from patients with RA and controls, was exclusive to five female patients. The dissimilarity between patients with RA and IA in their HLA associations was not reflected in different female to male ratios, however, as the ratio is $3: 1$ in both groups. The reasons for increased susceptibility to $R A$ and IA in women are not known but, in the absence 
of these female susceptibility genes, $\mathrm{MHC}$ genes may be more important in susceptibility of male patients to RA-for example, DR4, glyoxalase$1 / 2$, and to IA-for example, B27, B35, DR1, glyoxalase-1/2.

Most studies do not comment on HLA antigens particularly associated with mild arthritis, with the exception of B27 and its association with the 'seronegative spondarthritides'. ${ }^{27}$ Eleven of our patients with IA carried B27 but none of these, five to eight years after onset of symptoms, had sufficient features to diagnose ankylosing spondylitis. ${ }^{28}$ Some of these B27 positive patients with IA, however, had clinical features in common with ankylosing spondylitis: three had back pain aggravated by rest (six had mechanical type backache), six had iritis or conjunctivitis, one had enthesiopathy, and all had temporarily painful small or large joints. Possibly the presence of B27 in these patients increased the risk of onset of such symptoms, but other factors prevented the symptoms from developing into diagnosable disease.

At present MHC antigens cannot be used as prognostic tools at onset of mild inflammatory arthritis to distinguish those patients who will develop definite RA. The frequency of DR4 in the normal population is too high $(\simeq 40 \%)$ unlike that of $B 27(\simeq 8 \%)$ and the frequency of particular extended haplotypes in patients with RA, such as [B62 S33 DR4], is too low ( $\simeq 7 \%)$. Furthermore, in patients with IA no MHC antigen is sufficiently increased in frequency to act as a marker for IA.

In conclusion, although investigation of a patient's MHC antigens will not aid prognosis at the onset of symptoms, this study shows that HLA-DR4 and other MHC antigens associated with RA are only associated with susceptibility to the chronic condition and not with susceptibility to arthritis itself.

We are indebted to our patients and their family members for their generous donations of blood samples. We also thank Mrs Margaret Dugas, Mrs Celia Kerslake, and Mrs Pauline Hill, our phlebotomists, and Mrs Margaret Barker, our co-ordinator, for phlebotomists, and Mrs Margaret Barker, our co-ordinator, for
their time and skills given voluntarily. We are grateful to Mrs their time and skills given voluntarily. We are grateful to Mrs
Penny Sanders for her patience and skilful secretarial help. This work was supported by the Northcott Devon Medical Foundation, Medical Research Council, South Western Regional Health Authority, and the Wellcome Trust.

1 Stastny P. Association of B cell alloantigen DRw4 with rheumatoid arthritis. $N$ Engl f Med 1978; 298: 869-71.

2 Lanchbury J S S. Molecular genetics of the HLA-D region component of inherited susceptibility to rheumatoid arthritis. Brf Rheumatol 1988; 27: 171-5.

Br J Rheumatol 1988; 27: 171-5.
3 Jones V E, Jacoby R K, Johnson P M, Phua K K, Welsh K I. Association of HLA-DR4 with definite rheumatoid arthritis Association of HLA-DR4 with definite rheumatoid arthritis
but not with susceptibility to arthritis [Abstract]. Ann Rheum Dis 1983; 42: 223.

4 de Jongh B M, Westedt M L, de Vries R R P, Valkenburg
H A, Cats A. Genetic heterogeneity of rheumatoid arthritis. Dis Markers 1986; 4: 29-33.

5 Jaraquemada D, Ollier W, Awad J, Young A, Festenstein H. HLA and rheumatoid arthritis: susceptibility or severity. Dis Markers 1986; 4: 43-53.

6 Arnett F C, Edworthy S M, Bloch D A, et al. The American Rheumatism Association 1987 revised criteria for the classification of rheumatoid arthritis. Arthritis Rheum 1988; 31: $315-24$.

7 Ropes M W, Bennett G A, Cobb S, Jacox R, Jessar R A. Revision of diagnostic criteria for rheumatoid arthritis. Bull Rheum Dis 1958; 9: 175-6.

8 Puttick A H, Briggs D C, Welsh K I, Williamson E A, Jacoby $\mathrm{R} \mathrm{K}$, Jones V E. Genes associated with rheumatoid arthritis and mild inflammatory arthritis. II. Association of HLA with complement $\mathrm{C} 3$ and immunoglobulin $\mathrm{Gm}$ allotypes. Ann Rheum Dis 1990; 49: 225-8.

9 Puttick A, Briggs D, Welsh K, Jacoby R K, Williamson E A, Jones V E. Extended haplotypes in rheumatoid arthritis and preliminary evidence for interaction with immunoglobulin genes. Dis Markers 1986; 4: 139-44.

10 Jones V E, Jacoby R K, Wallington T, Holt P. Immune complexes in early arthritis. I. Detection of immune complexes in early arthritis. I. Detection of immune Immunol 1981; 44: 512-21.

11 Jones V E, Taylor P C R, Jacoby R K, Wallington T B. Synovial synthesis of rheumatoid factors and immune complex constituents in early arthritis. Ann Rheum Dis 1984; 43: 235-9.

12 Cohen B J, Buckley M M, Clewley J P, Jones V E, Puttick $A \mathbf{H}$, Jacoby $\mathbf{R} \mathrm{K}$. Human parvovirus infection in early rheumatoid and inflammatory arthritis. Ann Rheum Dis 1986; 45: 832-8.

13 Fielder A H I, Walport M J, Batchelor J R, et al. Family study of the major histocompatibility complex in patients with systemic lupus erythematosus: importance of null with systemic lupus erythematosus: importance of null BrMed F 1983; 286: 425-8.

14 Raum D, Awdeh Z, Yunis E J, Alper C A, Gabbay K H. Extended major histocompatibility complex haplotypes in type I diabetes mellitus. $\mathcal{f}$ Clin Invest 1984; 74: 449-54.

15 Demaine A G, Vaughan R W, Taube D H, Kerr L A P, Welsh K I. Immunoglobulin switch region polymorphisms are associated with autoimmune renal disease. Clin Exp Immunol 1986; 66: 406-13.

16 Bidwell J L, Bidwell E A, Savage D, Middleton P T, Klouda P, Bradley B A. A DNA-RFLP typing system that positively identifies serologically well-defined and ill-defined HLA-DR and -DQ alleles, including DRw10. Transplantation 1988; 45: 640-6.

17 Woodrow J C. Analysis of the HLA association with rheumatoid arthritis. Dis Markers 1986; 4: 7-12.

18 Raum D, Awdeh Z, Glass D, et al. Extended haplotypes of chromosome 6 in adult rheumatoid arthritis. Arthritis Rheum 1984; 27: 516-21.

19 McCluskey J, Kay P H, Dawkins R L, Komori K, Christiansen F T, McCann V J. Association of specific MHC supratypes with rheumatoid arthritis and insulin dependent diabetes mellitus. Dis Markers 1983; 1: 197-212.

20 Dyer P A, Thomson W, Sanders P A, Grennan D M. Are major histocompatibility system class III products independent markers for susceptibility to rheumatoid arthritis? Dis Markers 1986; 4: 151-5.

21 Lanchbury J S S, Pal B, Papiha S S. Bf and C3 polymorphisms in rheumatoid arthritis. Hum Hered 1987; 37: 144-9.

22 Thomson W, Sanders P A, Davis M, Davidson J, Dyer P A, Grennan D M. Complement C4B-null alleles in Felty's syndrome. Arthritis Rheum 1988; 31: 984-9.

23 Gran J T, Husby G. Seronegative rheumatoid arthritis and HLA DR4. Proposal for criteria. F Rheumatol 1987; 14: 1079-82.

24 Masi A T. Rheumatoid factor negative (seronegative) rheumatoid arthritis: evolving clinical classification and immunogenetic associations. $f$ Rheumatol 1988; 15: 4-6.

25 Black C M, Welsh K I, Maddison P, Jayson M I V, Bernstein $R M$. HLA antigens, autoantibodies and clinical subsets in scleroderma. Br $¥$ R heumatol 1984; 23: 267-71.

26 Hall P J, Burman S J, Laurent M R, et al. Genetic markers in pauciarticular onset juvenile chronic arthritis [Abstract]. pauciarticular onset juvenile

27 Neumann V, Wright V. Perspectives in aetiology of seronegative polyarthritis. Br $\mathcal{f}$ Rheumatol 1988; 27 (suppl 11): $1-5$.

28 Bennett P H, Wood P H N, eds. Population studies of the rheumatic diseases. Proceedings of the Third International Symposium, New York, 1966. Amsterdam: Excerpta Medica, 1968: 456. 